Article

\title{
An Effective, Economical and Ultra-Fast Method for Hydrophobic Modification of NCC Using Poly(Methylhydrogen)Siloxane
}

\author{
Xueqing You ${ }^{\dagger}$, Qingjian $\mathrm{Hu}^{\dagger}{ }^{\dagger}$, Xiaoyong Hu, Hanxian Chen, Wenbin Yang and Xinxiang Zhang * (D) \\ College of Material Engineering, Fujian Agriculture and Forestry University, Fuzhou 350002, China; \\ 15880884064@163.com (X.Y.); qjhu0215@163.com (Q.H.); hxy1198578262@163.com (X.H.); \\ hanxian1229@163.com (H.C.); fafuywb@163.com (W.Y.) \\ * Correspondence: xxzhang0106@163.com; Tel.: +86-158-8008-9609 \\ + These authors contributed to this work equally.
}

Received: 24 April 2019; Accepted: 17 May 2019; Published: 3 June 2019

check for updates

\begin{abstract}
Poor compatibility between nanocellulose crystals (NCCs) and major polymers has limited the application of NCC as bio-reinforcements. In this work, an effective and ultra-fast method was investigated to significantly improve the hydrophobicity of NCC by using poly(methylhydrogen)siloxane (PMHS) as modifier. PMHS possessed amounts of reactive $-\mathrm{Si}-\mathrm{H}$ groups and hydrophobic $-\mathrm{CH}_{3}$ groups. The former groups were reactive with the hydroxyl groups of NCC, while the latter groups afforded NCC very low surface energy. As the weight ratio of PMHS to NCC was only $0.0005 \%$, the hydrophobicity of NCC was significantly improved by increasing the water contact angle of NCC from $0^{\circ}$ to $134^{\circ}$. The effect of weight ratio of PMHS to NCC and the hydrogen content of -Si-H in PMHS on the hydrophobicity and thermal stability was investigated in detail by Fourier transform infrared spectroscopy (FTIR), (X-ray Diffraction) XRD and (thermogravimetric analysis) TGA. The results indicated that PMHS chains were covalently grafted onto NCC and PMHS modification improved the thermal stability of NCC.
\end{abstract}

Keywords: nanocellulose; hydrophobic; surface modification; poly(methylhydrogen)siloxane; thermal stability

\section{Introduction}

Nanocellulose crystals (NCCs), extracted from hierarchical structure of cellulose, demonstrate a number of advantages, such as exceptional mechanical properties, high aspect ratio, low density and availability [1-4]. Hence, they have been widely used as the reinforcements in bionanocomposites. However, their application is limited by poor compatibility between NCC and nonpolar polymer media or matrices due to polar properties of NCC [5]. Chemical modification of NCC was proposed to address this issue [6-16]. The methods for chemical modification of NCC include isocyanation [6], esterification [6], silanation [7-10], oxidation [11,12], and acylation [13-15]. Siqueira et al. [5] prepared hydrophobic NCC by using n-octadel isocyanate $\left(\mathrm{C}_{18} \mathrm{H}_{37} \mathrm{NCO}\right)$ as modifier. Lin et al. [10] realized very hydrophobic NCC by a two-step silanation method by using KH560 ( $\gamma$-(2,3-epoxyproxy) propytrimethoxysilane) as a linker and dodecyltrimethoxysilane (DTMOS) as hydrophobic modifier. Menezes et al. [15] modified NCC with organic fatty acid chlorides with different aliphatic chain length by using hexanoyl chloride, lauroyl chloride and stearoyl chloride as modifiers. These methods significantly improved the hydrophobicity of NCC. However, a complicated process was required, and the modifiers were quite expensive.

Among these modification methods, silanation modification of NCC has been gaining more and more attention [10,16,17]. Recently, NCC was reported to be modified by 
silylation using 3-aminopropyltriethoxysilane (APTES) [16] and 3-2-(2-aminoethylamino)ethylamino propyl-trimethoxysilane (TAMS) [17]. However, the hydrophobicity of modified NCC by APTES and TAMS should be improved. In this work, we describe an effective, economical and ultra-fast approach for hydrophobic modification of NCC by using PMHS as modifier. PMHS chains had many $\mathrm{Si}-\mathrm{H}$ groups and $-\mathrm{Si}-\mathrm{CH}_{3}$ groups. The $\mathrm{Si}-\mathrm{H}$ groups possessed ultra-high reactivity to hydroxyl groups of NCC in the presence of Karstedt catalyst and then the PMHS chains with low surface energy would be covalently grafted onto the surface of NCC. In addition, PMHS are mass-produced products in silicone industry and therefore are easily handled and inexpensive. Finally, the effect of weight ratio of PMHS to NCC and hydrogen content of -Si-H in PMHS on hydrophobicity and thermal stability of NCC was investigated in detail by FTIR (Fourier transform infrared spectroscopy), XRD (X-ray diffraction) and TGA (thermo gravimetric analyzer).

\section{Materials and Methods}

\subsection{Materials}

Microcrystalline cellulose (MCC) with particle size of $50 \mu \mathrm{m}$ was purchased from Huzhou Yinhuxinwang Chemical Co., Ltd., Huzhou, China. $\mathrm{H}_{2} \mathrm{SO}_{4}$ and hexane were of analytical grade and supplied by Sinpharm Chemical Reagent Co., Ltd., Shanghai, China. PMHS and Kastredt catalyst (platinum-1,3-divinyl-1,1,3,3-tetramethyldisiloxane) were supplied by Chenguang Research Institute of Chemical Industry, Chengdu, China.

\subsection{Preparation of NCC}

NCC was fabricated by Tang's method which included $\mathrm{H}_{2} \mathrm{SO}_{4}$ hydrolysis of MCC assisted with ultrasonic treatment [18]. $\mathrm{H}_{2} \mathrm{SO}_{4}$ hydrolysis was performed at $52{ }^{\circ} \mathrm{C}$ with $65 \mathrm{wt} \% \mathrm{H}_{2} \mathrm{SO}_{4}$ for $2 \mathrm{~h}$ under mechanical stirring. Then, the suspension was washed until neutrality by successive centrifugations at the relative centrifugal relative force (CRF) of 10,833 g and dialyzed against distilled water for 5 days. Finally, the NCC powders were obtained after freeze-drying.

\subsection{Hydrophobic Modification of NCC}

PMHS was used as hydrophobic surface modifier. The hydrogen contents of $-\mathrm{Si}-\mathrm{H}$ in PMHS was $0.18 \%, 1.0 \%$ and $1.5 \%$, and the resultant PMHS was named as $0.18 \%$ PMHS, $1.0 \%$ PMHS and $1.5 \%$ PMHS, respectively. The modifier solution was prepared by mixing $\mathrm{x} g$ PMHS, (50-x) $\mathrm{g}$ hexane and 2 droplets of Kastredt catalyst (platinum-1,3-divinyl-1,1,3,3-tetramethyldisiloxane) together. Then, $0.5 \mathrm{~g}$ of NCC powder was added to the modifier solution at room temperature for $10 \mathrm{~min}$ under vigorous mechanical stirring. The weight ratio of $0.18 \%$ PMHS to NCC in modifier solution was $5 \%$, $10 \%, 20 \%, 50 \%, 80 \%, 100 \%$ and $150 \%$, while that of $1.0 \%$ PMHS and $1.5 \%$ PMHS was both $0.0005 \%$, $0.001 \%, 0.005 \%, 0.01 \%, 0.05 \%, 0.2 \%$ and $0.5 \%$. After modification, the modified NCC were filtered with $0.22 \mu \mathrm{m}$ PVDF (polyvinylidene fluoride) filters and washed with hexane for three times.

\subsection{Characterization}

WCA (water contact angle) measurement was executed using the sessile drop configuration at room temperature on Krüss DSA-30 instrument (Hamburg, Germany) equipped with a CDD (Charge Coupled Device) camera. For WCA measurement, NCC powder was spread onto the surface of double-side tap. The volume of water droplets for all measurements was set at $5 \mu \mathrm{L}$. The dynamic contact along with time was recorded. The FTIR spectra of all samples were recorded between 400 and $4000 \mathrm{~cm}^{-1}$ using a Bruker Tensor 27 FTIR spectrophotometer. NCC, $0.18 \%$ PMHS, $1.0 \%$ PMHS and $1.5 \%$ PMHS modified NCC samples were respectively mixed with analytical grade KBr powders and then pressed into pellet. The total of 32 scans was obtained, using a resolution of $4 \mathrm{~cm}^{-1}$. The crystalline structure and crystallinity index (CrI) changes of the samples were tested by X-ray diffractometer (Rigaku D/Max-Ra, Rigaku, Toyko, Japan) analysis using $\mathrm{Cu} \mathrm{K} \alpha$ radiation. Test were taken from $2 \theta=6^{\circ}$ 
to $60^{\circ}$ at a step size of $0.1^{\circ}$. The CrI was calculated according to Segal's method [19]. The equation is an empirical method for evaluating the degree of crystallinity in the NCC.

$$
\operatorname{CrI}(\%)=\left(\mathrm{I}_{002}-\mathrm{I}_{\mathrm{am}}\right) / \mathrm{I}_{002} \cdot 100
$$

where $\mathrm{I}_{002}$ is the maximum intensity of the (002) lattice diffraction peak at $2 \theta \approx 22^{\circ}$ and $\mathrm{I}_{\mathrm{am}}$ is the lowest intensity at $2 \theta \approx 18^{\circ}$, representing the amorphous part of the sample. The thermal stability of the samples was investigated by TGA (Netasch, TG209 F1, Selb, Germany). The amount of sample taken for each test was approximately $5 \mathrm{mg}$. All tests were executed under a nitrogen atmosphere with a gas flow $10 \mathrm{~mL} / \mathrm{min}$ and heated from $30^{\circ} \mathrm{C}$ to $600^{\circ} \mathrm{C}$ at a heating rate of $10^{\circ} \mathrm{C} / \mathrm{min}$.

\section{Results and Discussion}

\subsection{Hydrophobicity of NCC}

The dynamic contact angle along with time was recorded and showed in Figures 1-3. Figure 1 showed the change in water contact angle of $0.18 \%$ PMHS modified NCC as a function of test time. For unmodified NCC, the water drop was adsorbed by NCC immediately within $40 \mathrm{~ms}$. Increasing the weight ratio of PMHS to NCC, the hydrophobicity of NCC was significantly improved. As the weight ratio of $0.18 \%$ PMHS to NCC lowered than $50 \%$, the water droplets would also adsorbed by the modified NCC. However, the adsorption process was obviously inhibited by $0.18 \%$ PMHS modification. The time for total adsorption of water droplets was significantly increased from $40 \mathrm{~ms}$ to $1900 \mathrm{~ms}$. As the weight ratio of $0.18 \%$ PMHS to NCC increased to $50 \%, 80 \%, 100 \%$ and $150 \%$, the modified NCC could obtain a stable water droplet, and the static contact angle was recorded to be $119^{\circ}, 127^{\circ}, 134^{\circ}$, $141^{\circ}$, respectively.

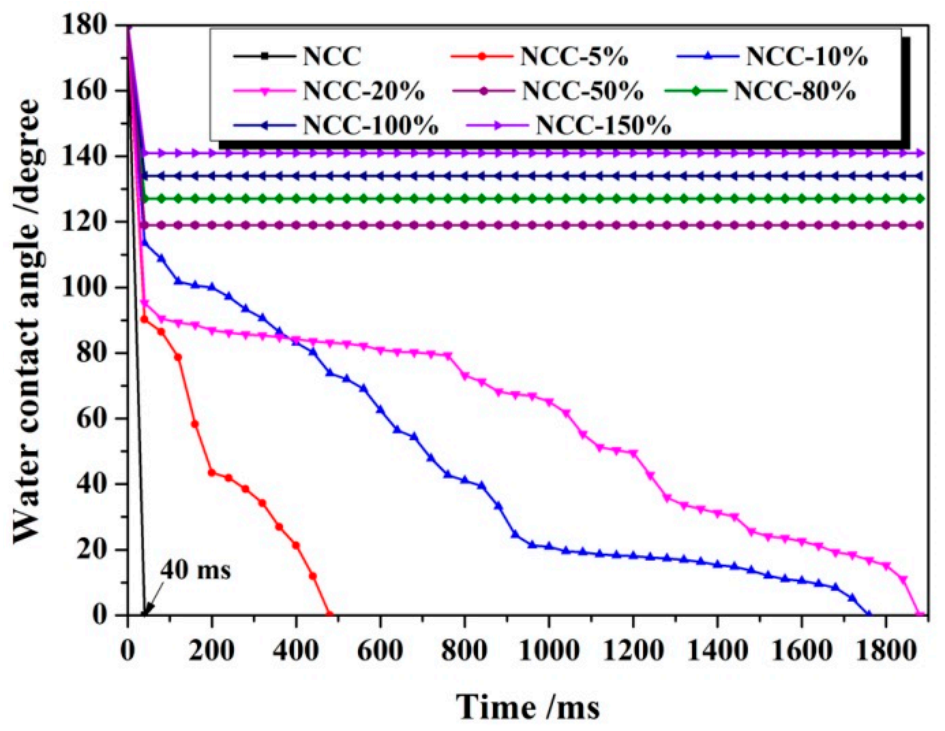

Figure 1. Dynamic contact angle of $0.18 \%$ PMHS modified NCC along with time.

Figure 2 showed the effect of weight ratio of $1.0 \%$ PMHS to NCC on the hydrophobicity of NCC. Compared with $0.18 \%$ PMHS, $1.0 \%$ PMHS was more effective in hydrophobic modification of NCC. As the weight ratio of $1.0 \%$ PMHS to NCC was only $0.05 \%$, the modified NCC presented a stable water droplet on its surface, and the static water contact angle was $136^{\circ}$.

Figure 3 revealed the effect of weight ratio of 1.5\% PMHS to NCC on the hydrophobicity of NCC. As showed in Figure 3, 1.5\%PMHS was an excellent hydrophobic modifier for NCC. As the weight ratio of $1.5 \%$ PMHS to NCC was only $0.0005 \%$, the modified NCC was totally hydrophobic with a water contact angle of $134^{\circ}$. As the weight ratio of $1.5 \%$ PMHS to NCC was increased further 
to $0.5 \%$, the water contact angle was gradually increased to $147^{\circ}$. Finally, it could be concluded that $1.5 \%$ PMHS was the best candidate for hydrophobic modification of NCC, and it can be inferred that the modification efficiency of NCC by PMHS increased with hydrogen content of -Si-H in PMHS.

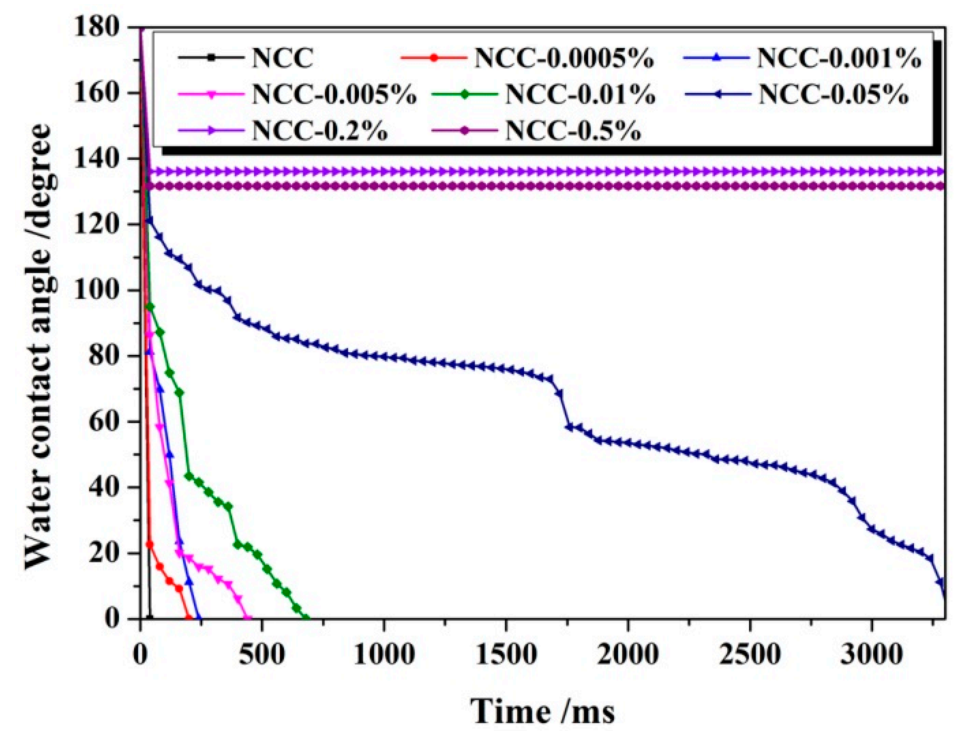

Figure 2. Dynamic contact angle of 1.0\%PMHS modified NCC along with time.

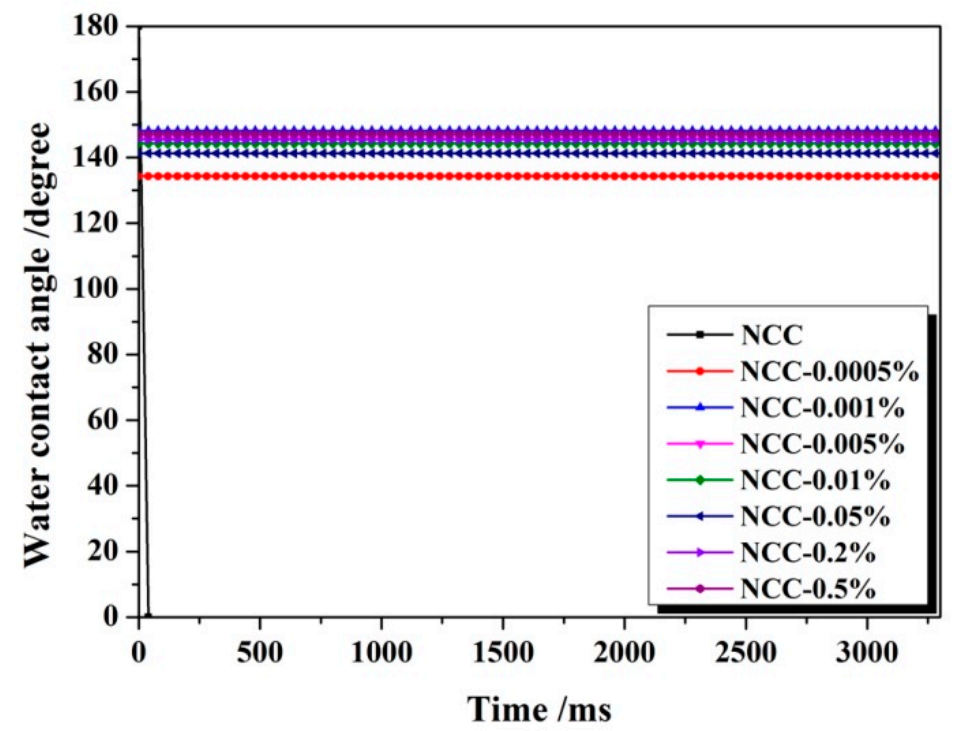

Figure 3. Dynamic contact angle of 1.5\%PMHS modified NCC along with time.

\subsection{FTIR Characterization}

According to the chemical structure of PMHS, it could be deduced that, after PMHS modification, there would be lots of hydrophobic $-\mathrm{Si}-\mathrm{CH}_{3}$ groups grafted onto the surface of NCC and corresponding absorption bands in FTIR spectra. Figure 4 showed the change in chemical composition of NCC before and after PMHS modification. After PMHS modification, the modified NCC had been washed by hexane for three times to remove PMHS which was not grafted onto NCC. Compared to the unmodified NCC, the PMHS modified NCC showed additional absorption band at $2855 \mathrm{~cm}^{-1}$. Absorption band at $2855 \mathrm{~cm}^{-1}$ was assigned to the $-\mathrm{Si}-\mathrm{CH}_{3}$ groups [20]. In addition, during modification process, lots of bubbles were observed due to the dehydrogenation between -Si-H of PMHS and -OH of NCC. Therefore, it can be concluded that the PMHS chains were covalently grafted onto the surface of NCC, which improved significantly the hydrophobicity of NCC. 


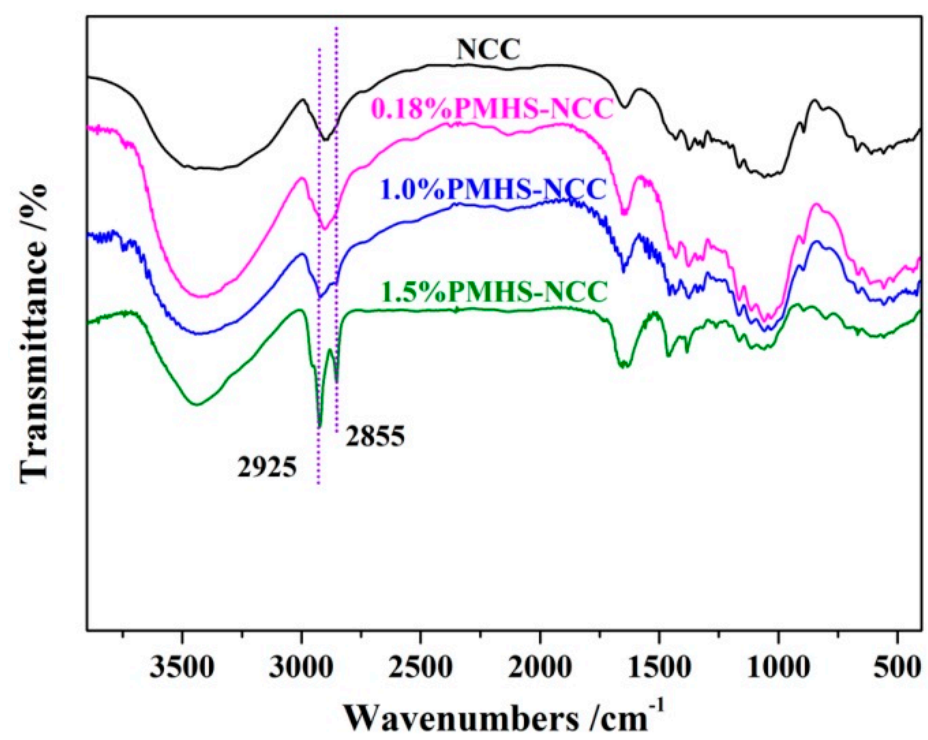

Figure 4. The FTIR spectra of unmodified NCC and NCC modified by $0.18 \% \mathrm{PMHS}, 1.0 \% \mathrm{PMHS}$ and $1.5 \%$ PMHS.

Figure 4 also revealed that the intensity of absorption bands at $2855 \mathrm{~cm}^{-1}$ increased with increasing hydrogen content of $-\mathrm{Si}-\mathrm{H}$ in PMHS. This was in good agreement with results of water contact angle, in which 1.5\%PMHS was demonstrated to be the best modifier for NCC.

\subsection{Difference in PMHS Structure}

As discussed before, the modification efficiency of NCC with PMHS was closely related to hydrogen content of $-\mathrm{Si}-\mathrm{H}$ in PMHS. PMHS is a dimethyl polysiloxane with the general structure of $\left(\mathrm{CH}_{3}\right)_{3} \mathrm{SiO}\left(\mathrm{CH}_{3} \mathrm{HSiO}\right)_{m}\left(\left(\mathrm{CH}_{3}\right)_{2} \mathrm{SiO}\right)_{n} \mathrm{Si}\left(\mathrm{CH}_{3}\right)_{3}$ [21]. There are two kinds of repeat units on the PMHS molecule, which contains abundant reactive $\mathrm{Si}-\mathrm{H}$ groups and hydrophobic $-\mathrm{CH}_{3}$ groups. Figure $5 \mathrm{a}$ is the chemical structure of 1.5\%PMHS. 1.5\%PMHS is the concentrated hydrogen silicone oil, which has no $-\mathrm{Si}\left(\mathrm{CH}_{3}\right)_{2} \mathrm{O}$ - repeat unit. The number of repeat unit " $\mathrm{m}$ " can be calculated to be 24 . As shown in Figure 5b, 1.0\%PMHS and 0.2\%PMHS were derived from the concentrated hydrogen silicone oil (1.5\%PMHS), and the number of repeat units of $-\left(\mathrm{CH}_{3}\right)_{2} \mathrm{SiO}-$ could be calculated to be 11 and 159 , respectively. Without regard to the bond angle of $-\mathrm{Si}-\mathrm{O}-\mathrm{Si}-$ and $-\mathrm{Si}-\mathrm{O}-\mathrm{C}-$, the theoretical extended length of $0.18 \%$ PMHS, 1.0\%PMHS and 1.5\%PMHS is estimated to $60.7 \mathrm{~nm}, 12.2 \mathrm{~nm}$ and $8.6 \mathrm{~nm}$, respectively (the bond length of $\mathrm{Si}-\mathrm{O}$ and $\mathrm{Si}-\mathrm{C}$ is $0.164 \mathrm{~nm}$ and $0.186 \mathrm{~nm}$, respectively). The most striking difference of three kinds of PMHS was the chain lengths and the hydrogen content of $-\mathrm{Si}-\mathrm{H}$. The chain length of $0.18 \%$ PMHS was 7 times longer than that of $1.5 \%$ PMHS.

As shown in Figure 5c, before PMHS modification, the surface of NCC was abundant in hydroxyl groups, resulting in a very hydrophilic property of NCC. After PMHS modification, PMHS chains with amounts of hydrophobic methyl groups were grafted onto the surface of NCC. This was in good agreement with results from water contact angle characterization. In addition, as shown in Figure $5 c$, PMHS with different chemical structure had different modification efficiency on NCC. The chemical structure of $1.5 \% \mathrm{PMHS}$ revealed that PMHS chain was only consisted of $-\mathrm{CH}_{3} \mathrm{HSiO}$ - units. In addition, $1.5 \%$ PMHS chain was short, and therefore the 1.5\%PMHS chains could react more effectively with the $-\mathrm{OH}$ groups on NCC surface. Therefore, as showed in Figure $5 \mathrm{c}$, more -OH groups on surface of NCC were replaced by PMHS chains. However, for $0.18 \%$ PMHS, it was much longer and had amounts of inert $-\mathrm{CH}_{3} \mathrm{HSiO}$ - units. As showed in Figure $5 \mathrm{c}$, due to the steric hindrance of inert - $\mathrm{Si}\left(\mathrm{CH}_{3}\right)_{2} \mathrm{O}$ - units and long PMHS chain length, the dehydrogenation between $0.18 \%$ PMHS and NCC was hindered, and hence, the modification efficiency was worse than that of 1.5\%PMHS. 


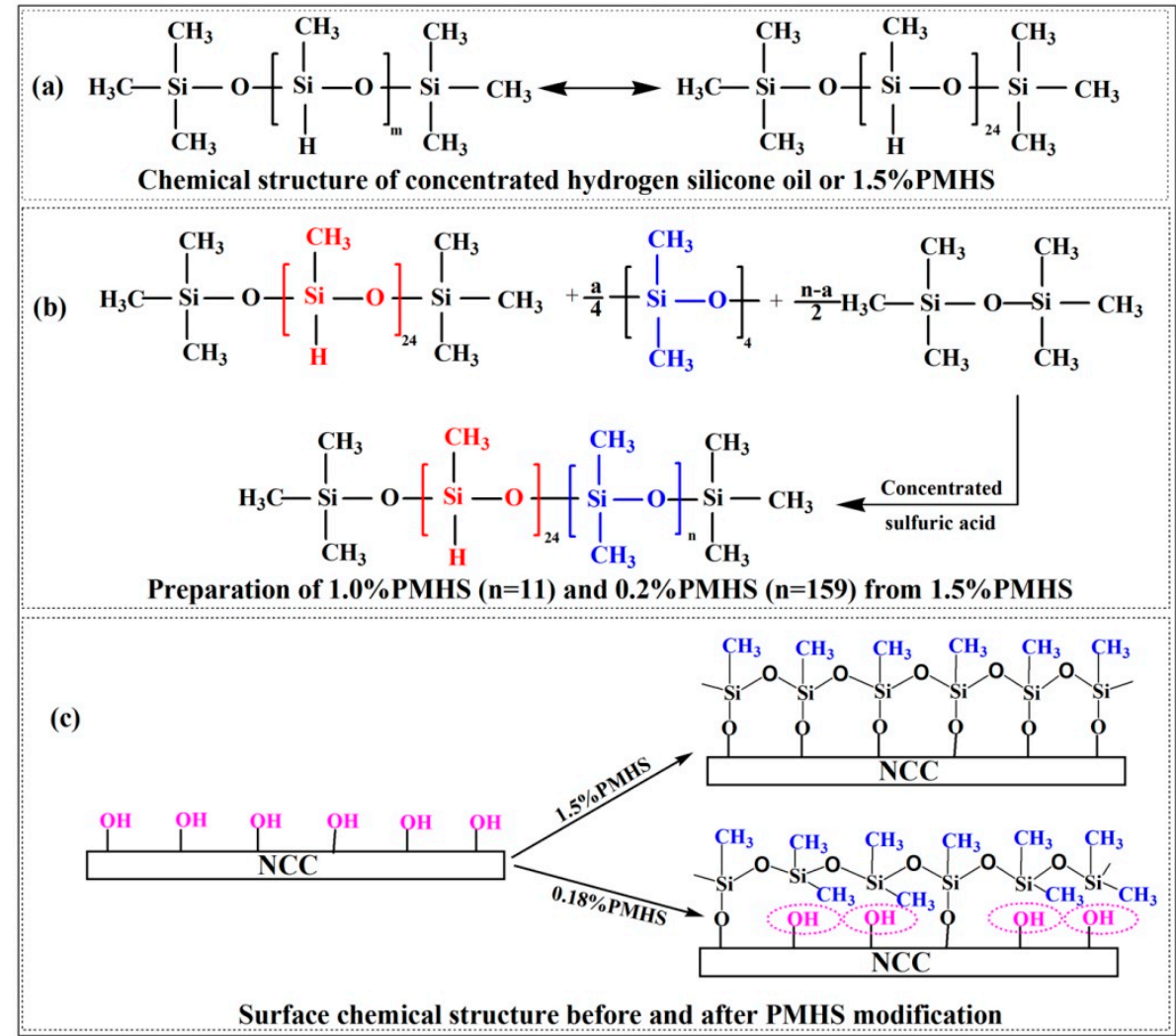

Figure 5. Chemical structure of 1.5\%PMHS (a); Preparation of 1.0\%PMHS and 0.2\%PMHS from $1.5 \%$ PMHS (b); Surface chemical structure before and after PMHS modification (c).

\subsection{Crystallinity of NCC}

Chemical modification performed on NCC could affect the crystallinity of cellulose [22]. To investigate the effect of PMHS modification on crystalline properties of NCC, the crystallinity index and crystalline dimensions in different planes of NCC were estimated by X-ray diffraction analysis. As showed in Figure 6, all samples had similar diffraction patterns with four diffraction peaks at $2 \theta=15.2^{\circ}, 16.2^{\circ}, 22.8^{\circ}$ and $34.7^{\circ}$, corresponding to the diffraction planes of $101,10 \overline{1}, 002$ and 004 crystallographic planes, respectively, which were in agreement with the characteristic diffraction peaks of cellulose I $[15,23]$. This indicated that the crystalline type of cellulose is not altered after PMHS modification. No peak shifting or appearance of new peaks was observed. This is further evidence to suggest that the surface modification of NCC with PMHS occurred essentially only on the surface of NCC [24]. The crystallinity of NCC before and after PMHS modification as determined using the Segal-equation is presented in Table 1. It could be seen that the PMHS modification led to a slight decrease in the NCC crystallinity.

Table 1. Degree of crystallinity, crystalline dimensions, the number of hydroxyl groups per unit surface area $\left(\mathrm{N}_{0}\right)$ and weight lose between $238-146^{\circ} \mathrm{C}$ for unmodified and modified NCC.

\begin{tabular}{|c|c|c|c|c|c|c|}
\hline \multirow{2}{*}{ Sample } & \multirow{2}{*}{$x_{c}$} & \multicolumn{3}{|c|}{ Crystalline Dimensions (nm) } & \multirow{2}{*}{$\begin{array}{c}\mathrm{N}_{0} \cdot 10^{-3} \\
\left(\mathrm{mmol} \cdot \mathrm{m}^{-2}\right)\end{array}$} & \multirow{2}{*}{$\begin{array}{c}\text { Weight } / \% \\
\left(238-416^{\circ} \mathrm{C}\right)\end{array}$} \\
\hline & & $\{101\}$ & $\{10 \overline{1}\}$ & $\{002\}$ & & \\
\hline NCC & $78.51 \%$ & 6.7 & 8.3 & 8.0 & 6.656 & 46.35 \\
\hline $0.18 \%$ PMHS-NCC & $76.59 \%$ & 7.0 & 8.4 & 8.3 & 6.472 & 46.24 \\
\hline 1.0\%PMHS-NCC & $74.90 \%$ & 7.5 & 8.0 & 8.2 & 6.430 & 53.97 \\
\hline 1.5\%PMHS-NCC & $73.71 \%$ & 7.4 & 11.5 & 8.2 & 5.273 & 54.46 \\
\hline
\end{tabular}




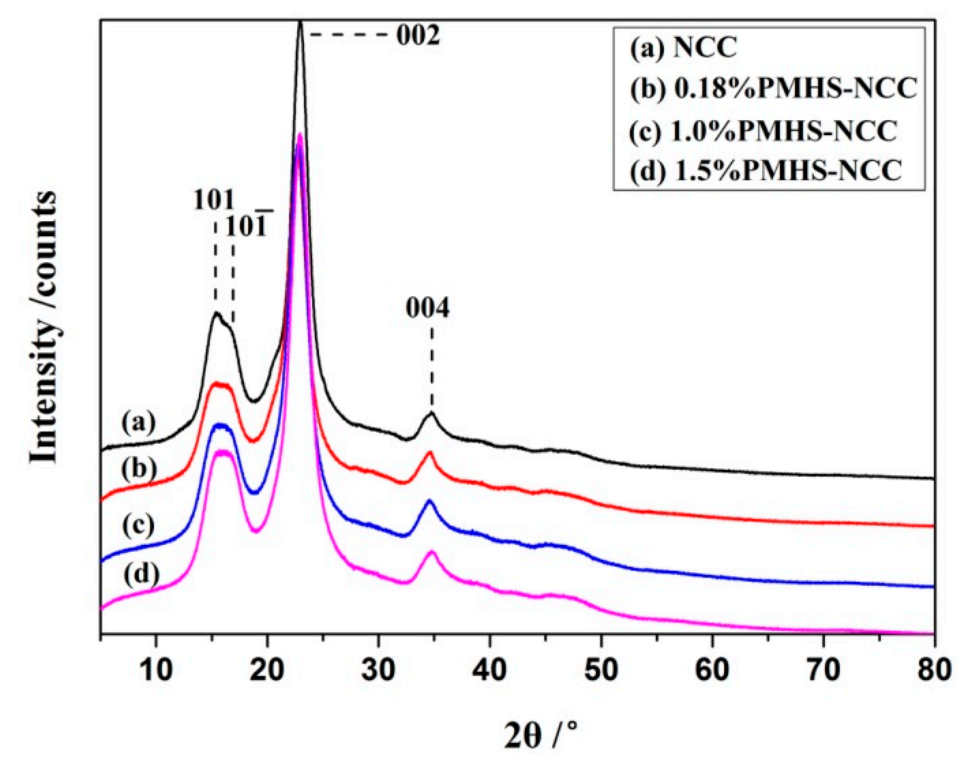

Figure 6. XRD patterns of NCC before and after PMHS modification.

Crystalline dimension for (110), (101), and (200) planes of NCC before and after PMHS modification can be obtained from XRD measurement, and data are showed in Table 1. According to prior report [23], the number of hydroxyl groups per unit surface area $\left(N_{0}\right)$ on NCC can be calculated according to follow equation.

$$
\begin{gathered}
N_{0}=\frac{120(\mathrm{OH})}{N_{A}\left(2 A_{101}+2 A_{10 \overline{1}}\right)} \\
N_{A}=6.02 \cdot 10^{23} \text { (Avogadro's number) }
\end{gathered}
$$

It is observed that the values for $N_{0}$ decreased with increasing hydrogen content of $-\mathrm{Si}-\mathrm{H}$ in PMHS. This result is in good agreement with the results discussed earlier.

\subsection{Thermal Stability of NCC}

Thermal stability is also a vital factor, especially when NCC is worked as reinforcement for polymers because elevated temperatures is a necessary for melt processing [22]. The crystallinity of NCC is high due to the hydrolysis of amorphous region of cellulose, and therefore the thermal stability of NCC is good while compared with many other biomaterials. However, as discussed before, PMHS modification slightly decreased the crystallinity of NCC, and the effect of PMHS modification on thermal stability of NCC should be carried out. Figure 7a showed the thermal degradation behavior of NCC before and after PMHS modification. All sample displayed a weight loss from room temperature to $186{ }^{\circ} \mathrm{C}$. It was ascribed to the evaporation of absorbed water because of the hydrophilic character of the NCC surface [15]. This effect was decreased significantly for the sample with PMHS modification. It was obviously ascribed to a lower accessibility of NCC surface to water after the PMHS modification [22]. In addition, as the hydrogen content of -Si-H in PMHS increased from $0.18 \%$ to $1.5 \%$, the weight loss of physically absorbed water decreased obviously from $6.14 \%$ to $4.17 \%$. This is in good agreement with results from FTIR and WCA characterization, in which more hydrophobic $-\mathrm{CH}_{3}$ groups and better hydrophobicity were observed for $1.5 \%$ PMHDS modified NCC. Thermal decomposition of all spectra began at temperature around $186^{\circ} \mathrm{C}$. The weight loss of stage $\mathrm{B}$ between $186-238^{\circ} \mathrm{C}$. corresponded to glucose dehydration. Then a higher weight loss was observed in the range $238-416^{\circ} \mathrm{C}$. (stage C). The weight loss results were listed in Table 1. A comparison of PMHS modified NCC to unmodified NCC showed increased weight loss between $238^{\circ} \mathrm{C}$ and $416^{\circ} \mathrm{C}$, indicating the decomposition of methyl groups for PMHS chains. In Figure $7 \mathrm{~b}$, it could be seen that the 
corresponding endothermic peak of DSC curve at around $250{ }^{\circ} \mathrm{C}$. These results implied that the PMHS modification had little damage on the thermal stability of NCC.
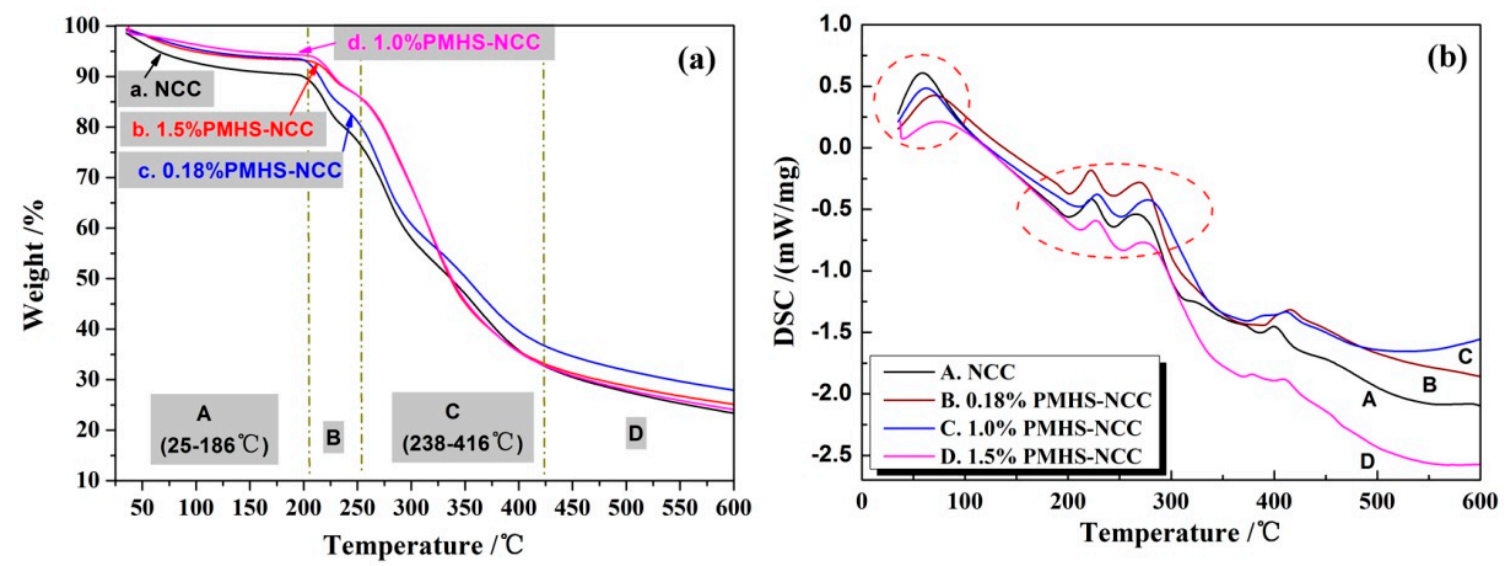

Figure 7. TG curves (a) and DSC curves (b) for unmodified and modified NCC.

\section{Conclusions}

An effective, economical and ultra-fast method was investigated to modify nanocellulose crystal (NCC) using poly(methylhydrogen)siloxane (PMHS) as modifier. PMHS modification significantly improved the hydrophobicity of NCC by increasing its water contact angle from 0 to about 140 . The hydrophobic modification efficiency of NCC is proportional to the hydrogen content of $-\mathrm{Si}-\mathrm{H}$ in PMHS. PMHS chains were covalently grafted onto the surface of NCC by dehydrogenation between -Si-H of PMHS and -OH of NCC. After PMHS modification, the crystallinity of NCC slightly decreased, while the thermal stability was almost unaffected.

Author Contributions: Data curation, X.Y. and Q.H.; Formal Analysis, X.H.; Writing-Original Draft, H.C., W.Y.; Writing-Review \& Editing, X.Z.

Funding: This research was funded by [Outstanding Youth Fund of Fujian Agriculture and Forestry University of China] grant number [XJQ201602] and [National Natural Science Foundation of China] grant number [61505029].

Conflicts of Interest: The authors declare no conflict of interest. The funders had no role in the design of the study; in the collection, analyses, or interpretation of data; in the writing of the manuscript, and in the decision to publish the results.

\section{References}

1. Dufresne, A. Nanocellulose: a new ageless bionanomaterial. Mater. Today 2013, 16, 220-227. [CrossRef]

2. Shang, W.L.; Huang, J.; Luo, H.; Chang, P.R.; Feng, J.W.; Xie, G.Y. Hydrophobic modification of cellulose nanocrystal via covalently grafting of castor oil. Cellulose 2013, 20, 179-190. [CrossRef]

3. Lin, N.; Huang, J.; Dufresne, A. Preparation, properties and applications of polysaccharide nanocrystals in advanced functional nanomaterials: a review. Nanoscale 2012, 4, 3274-3294. [CrossRef] [PubMed]

4. Kim, B.Y.; Han, S.Y.; Park, C.W.; Chae, H.M.; Lee, S.H. Preparation and properties of cellulose nanofiber films with various chemical compositions impregnated by ultraviolet-curable resin. Bioresources 2017, 12, 1767-1778. [CrossRef]

5. Siqueira, G.; Bras, J.; Dufresne, A. New Process of Chemical Grafting of Cellulose Nanoparticles with a Long Chain Isocyanate. Langmuir 2010, 26, 402-411. [CrossRef] [PubMed]

6. Lin, N.; Dufresne, A. Surface chemistry, morphological analysis and properties of cellulose nanocrystals with gradiented sulfation degrees. Nanoscale 2014, 6, 5384-5393. [CrossRef] [PubMed]

7. Goussé, C.; Chanzy, H.; Excoffier, G.; Soubeyrand, L.; Fleury, E. Stable suspensions of partially silylated cellulose whiskers dispersed in organic solvent. Polymer 2002, 43, 2645-2651. [CrossRef]

8. Frone, A.N.; Berlioz, S.; Chailan, J.F.; Panaitescu, D.M.; Donescu, D. Cellulose fiber-reinforced polylactic acid. Polym. Compos. 2011, 32, 976-985. [CrossRef] 
9. De Oliveira Taipina, M.; Ferrarezi, M.M.F.; Yoshida, I.V.P.; do Carmo Gonçalves, M. Surface modification of cotton nanocrystals with a silane agent. Cellulose 2013, 20, 217-226. [CrossRef]

10. Lin, W.; Hu, X.; You, X.; Sun, Y.; Wen, Y.; Yang, W.; Zhang, X.; Li, Y.; Chen, H. Hydrophobic modification of nanocellulose via a two-step silanation method. Polymers 2018, 10, 1035. [CrossRef]

11. Isogai, A.; Saito, T.; Fukuzumi, H. TEMPO-oxidized cellulose nanofibers. Nanoscale 2011, 3, 71-85. [CrossRef] [PubMed]

12. Inamochi, T.; Funahashi, R.; Nakamura, Y.; Saito, T.; Isogai, A. Effect of coexisting salt on TEMPO-mediated oxidation of wood cellulose for preparation of nanocellulose. Cellulose 2017, 24, 4097-4101. [CrossRef]

13. Huang, F.; Wu, X.; Yu, Y.; Lu, Y.; Chen, Q. Acylation of cellulose nanocrystals with acids/trifluoroacetic anhydride and properties of films from esters of CNCs. Carbohydr. Polym. 2017, 155, 525-534. [CrossRef]

14. Johnson, R.K.; Zink-Sharp, A.; Glasser, W.G. Preparation and characterization of hydrophobic derivatives of TEMPO-oxidized nanocelluloses. Cellulose 2011, 18, 1599-1609. [CrossRef]

15. De Menezes, A.J.; Siqueira, G.; Curvelo, A.A.S.; Dufresne, A. Extrusion and characterization of functionalized cellulose whiskers reinforced polyethylene nanocomposites. Polymer 2009, 50, 4552-4563. [CrossRef]

16. Khanjanzadeh, H.; Behrooz, R.; Bahramifar, N.; GindlAltmutter, W.; Bacher, M.; Edler, M.; Griesser, T. Surface chemical functionalization of cellulose nanocrystals by 3-aminopropyltriethoxysilane. Int. J. Biol. Macromol. 2018, 106, 1288-1296. [CrossRef]

17. Saini, S.; Naceur, M.; Bras, J. Effect of variable aminoalkyl chains on chemical grafting of cellulose nanofiber and their antimicrobial activity. Mater. Sci. Eng. C 2017, 75, 760-768. [CrossRef]

18. Tang, L.R.; Huang, B.; Ou, W.; Chen, X.R.; Chen, Y.D. Manufacture of cellulose nanocrystals by cation exchange resin-catalyzed hydrolysis of cellulose. Bioresour. Technol. 2011, 102, 10973-10977. [CrossRef]

19. Segal, L.; Cheely, J.J.; Martin, A.E.; Conrad, C.M. An empirical method for estimating the degree of crystallinity of native cellulose using X-ray diffractometer. Text. Res. J. 1959, 29, 786-794. [CrossRef]

20. Liu, J.H.; Zhang, L.; Zha, D.C.; Chen, L.Q.; Chen, X.X.; Qi, Z.M. Biosorption of malachite green onto Haematococcus pluvialis observed through synchrotron Fourier-transform infrared microspectroscopy. Lett. Appl. Microbiol. 2018, 67, 348-353. [CrossRef]

21. Sun, Y.; Zheng, J.; Huang, R.; Zhang, X.; Chen, C.; Jiang, B.; Chen, H.X.; Yan, L.H.; Yang, W.B. A simple method to control the microstructure and properties of sol-gel silica antireflective coatings. RSC Adv. 2017, 7, 31950-31959. [CrossRef]

22. Johar, N.; Ahmad, I.; Dufresne, A. Extraction, preparation and characterization of cellulose fibres and nanocrystals from rice husk. Ind. Crop. Prod. 2012, 37, 93-99. [CrossRef]

23. Lee, K.Y.; Quero, F.; Blaker, J.J.; Hill, C.A.S.; Eichhorn, S.J.; Bismarck, A. Surface only modification of bacterial cellulose nanofibres with organic acids. Cellulose 2011, 18, 595-605. [CrossRef]

24. Goswami, D.; Medda, S.K.; De, G. Superhydrophobic films on glass surface derived from trimethylsilanized silica gel nanoparticles. ACS Appl. Mater. Interfaces 2011, 3, 3440-3447. [CrossRef] [PubMed] 